\title{
Special issue: 125 years of high-mountain research at Sonnblick Observatory (Austrian Alps)
}

\author{
Hartmut GraßI - Michael Hantel - Mathias W. Rotach • \\ Ernest Rudel
}

Published online: 9 November 2012

(C) Springer-Verlag Wien 2012

It was in 1886 when the Sonnblick Observatory, in the Austrian Alps, was built through the fortunate circumstances that the idea of meteorologist Julius Hann was brought into practice by the local gold miner Ignaz Rojacher (Fig. 1). This was at a time when people thought that it is impossible to survive the harsh winter months with the extreme climate conditions at such elevations. Until today everyday live at the observatory has changed significantly. It moved to an outstanding research platform with cable car access, power supply, internet connection, etc., but it is still remote-not only for people but also from local pollution sources, which makes it an ideal place for environmental research (Fig. 2). The celebration of the 125th anniversary was not only a ceremonial act at the observatory but also the occasion for an international conference on "Climate Change in High Mountain Regions" in the City of Salzburg in September 2011. The response to the announcement of

the conference was overwhelming, thus indicating the high relevance of this topic in climate research. In particular, the high interest was not only triggered from the subject of the conference in general, but also from the unique role of the mountain observatories they play in studies on process understanding of climate change based on long-term measurements. On the one hand side, the success of the Salzburg conference was due to the high level of scientific contributions from participants at international level. On the other hand, the conference got substantial financial support from the Austrian Federal Ministry of Science and Research and from the Mountain Research Initiative (based in Switzerland).

The authors of the most outstanding presentations of the Salzburg Conference were invited by the editors to submit an article for this special issue of TAC. All the articles went through the normal reviewing process of the journal.

H. Graß1

Max Planck Institute for Meteorology,

Hamburg, Germany

\section{Hantel}

Theoretical Meteorology Research Forum, University of Vienna,

Vienna, Austria

e-mail: michael.hantel@univie.ac.at

\section{W. Rotach}

Institute for Meteorology and Geophysics,

University of Innsbruck,

Innsbruck, Austria

e-mail: mathias.rotach@uibk.ac.at

E. Rudel $(\triangle)$

Daten, Methoden und Modelle,

Zentralanstalt für Meteorologie und Geophysik

(Austrian National Meteorological Office),

Vienna, Austria

e-mail: ernest.rudel@zamg.ac.at

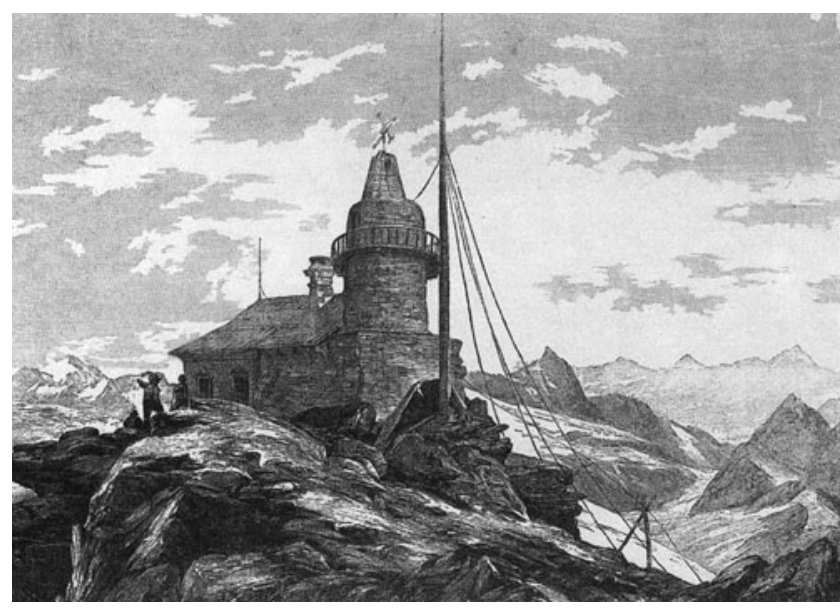

Fig. 1 Sonnblick Observatory in the Austrian Alps in 1886 - "Copyright Sonnblick Verein" 
Fig. 2 Current Sonnblick

Observatory in the Austrian

Alps - "Copyright ZAMG"

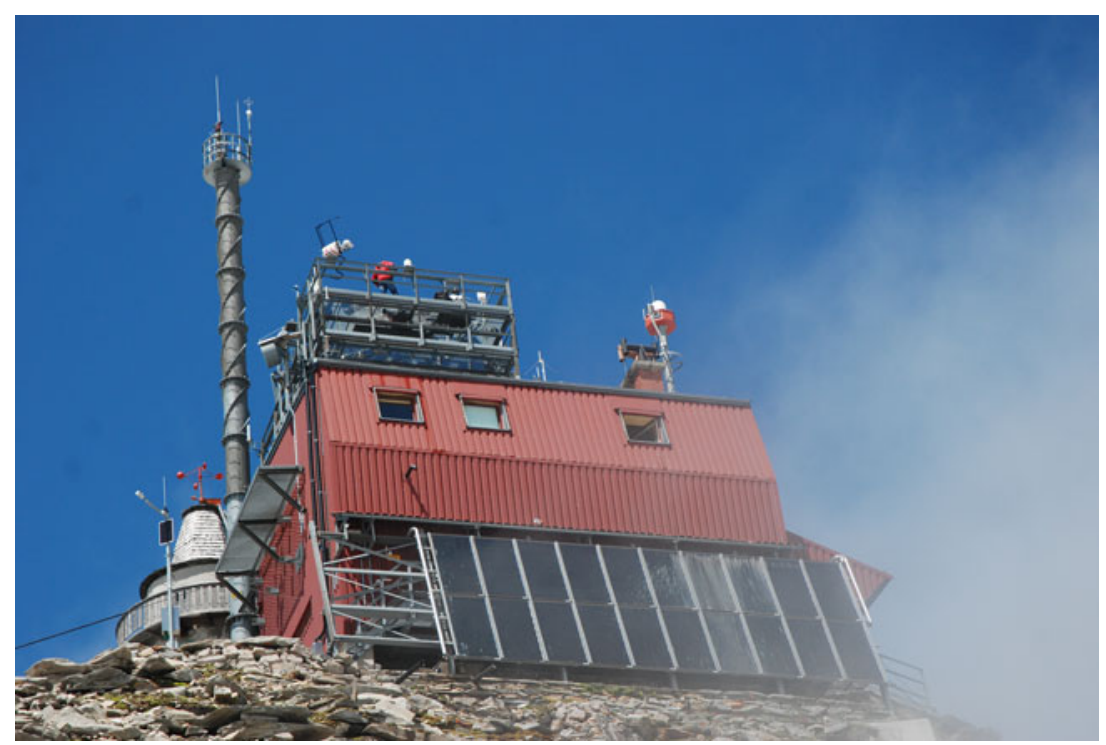

